\title{
Exposure to aerosol pollution and reported respiratory symptoms among segments of urban and rural populations in Sri Lanka
}

\author{
G.B.S. Perera, R. Emmanuel, Y.L.S. Nandasena, H.D.S. Premasiri
}

\begin{abstract}
Health effects due to exposure to air pollution have become a growing concern as an ill-effect of rapid urbanization in several regions of Sri Lanka. Evidence suggests that exposure to particulate matter and other aerosols such as $\mathrm{SO}_{2}$ and NOx have increased in urbanized areas in Sri Lanka. But presently adequate evidence to show the association between health effects and air pollution is not available.
\end{abstract}

In this ecological study, we present the micro-level picture of aerosol pollution obtained by using an interviewer administered questionnaire survey and comparing the results against exposure to aerosols. Secondary data were gathered on Sri Lankan health issues from the Ministry of Health to understand the most common causes of mortality and morbidity in the city.

Symptoms and the medical diagnosis information were collected from randomly selected probability proportionate samples of five categories of street users (commuters in buses, three wheelers, outdoor venders, shop keepers and residents) in an urbanized area of Colombo and in a rural area of a peripheral district. Exposure levels were measured using passive air samplers in both locations. Moreover active sampling measurements of curbside levels of Total Suspended Particulate Matters (TSP), Sulfur Dioxide $\left(\mathrm{SO}_{2}\right)$ and Nitrogen Dioxide $\left(\mathrm{NO}_{2}\right)$ were collected in urbanized area.

Aerosol exposure of urban and rural dwellers in all five categories, have shown significant differences in levels of SO $(p=0.001)$ and $\mathrm{NO}_{2}(p<0.001)$. Three wheeler drivers and shop keepers showed no significant difference in $\mathrm{SO}_{2}^{2}$ levels in both locations $\left(\mathrm{p}=0.045\right.$ and $p=0.113$ ) while buses at both locations showed the highest $\mathrm{NO}_{2}$ and $\mathrm{SO}_{2}$ levels at both sites while houses had the lowest levels. Further analysis showed that the exposure levels of bus drivers significantly vary $\left(\mathrm{SO}_{2}, \mathrm{~F}=13.399, \mathrm{p}=0.001 ; \mathrm{NO}_{2}, \mathrm{~F}=52.283, \mathrm{p}<0.001\right)$ on the route characteristics (urban, urban to sub urban and rural).

Urban street users had higher prevalence of cough $(\mathrm{p}<0.001, \mathrm{OR}=3.43, \mathrm{Cl}=2.29-5.15)$ and phlegm $(p<0.001, \mathrm{OR}=2.19, \mathrm{Cl}=2.29-5.15)$. Wheezing among city dwellers was $20.5 \%$ and among rural dwellers was $13.7 \%(p=0.043, O R=1.62, \mathrm{Cl}=0.99-2.67)$. There was no significant difference in breathlessness over the different locations.

The association might be overridden by localized risk factors such as difference in lifestyles among the urban and rural populations such as the higher number of people using wood as cooking fuel being in the rural site.

Short- and long-term mitigation strategies are needed to reduce people's exposure to such air pollutants. The outcome of this study has been extended for necessary policy implications and mitigation guidelines by introducing recommendations of land use development in the city limits.

\section{Introduction}

Air pollutants can cause a variety of health problems, including breathing problems, asthma, reduced lung function, lung damage, bronchitis, cancer, brain and nervous system damage. At the very minimum, they irritate the eyes, nose and throat, and reduce resistance to colds and other illnesses. Air pollution can be especially harmful to the very young, the very old, and those with certain pre-existing medical conditions.

Respirable particulate matter (i.e. particulates less than 10 microns fine particles, or 2.5 microns in aerodynamic diameter - ultra-fine particles - $\mathrm{PM}_{10}$ and $\mathrm{PM}_{2.5}$ respectively) may affect the health effects by by three different mechanisms (Prins et al., 1984): a direct mechanical (irritation) effect on the respiratory tract; a direct (systemic) toxic effect; and an indirect effect as carrier of toxic compounds. Two types of effects are generally considered; acute effects resulting from shortterm exposures to temporary high concentrations of pollutants, and chronic effects resulting from long-term exposure to lower-levels of pollutants (Safetyline Institute, 1993). Both acute and chronic effects can be reflected in high mortality rates, increased incidence of respiratory disease and reduced lung function. 
There is evidence that the levels of aerosol pollution, especially respirable particulate matter has increased in recent years in urban Sri Lanka (CEA, 2003). At the same time, there is an increasing prevalence of respiratory and cardiovascular diseases in Sri Lanka. If these are related, short- and long-term strategies will be needed to reduce people's exposure to such air pollutants. This will involve a range of policy and design options ranging from the re-designing of city streets to fuel pricing policy and vehicle importation policies.

\section{Background}

Air pollutants have been categorized based on different concepts. From an urban transportation point of view, it is useful to categorize air pollutants as follows:

Green House Gases (GHG's) - Carbon Dioxide $\left(\mathrm{CO}_{2}\right)$, Carbon Monoxide (CO), Nitrous Oxide $\left(\mathrm{N}_{2} \mathrm{O}\right)$, Chlorofluorocarbons (CFCs),

Aerosols - Sulfur Dioxide $\left(\mathrm{SO}_{2}\right)$, Particulate Matter (PM)

Radiative forcing Agents - Ozone $\left(\mathrm{O}_{3}\right) /$ tropospheric ozone $\left(\mathrm{O}_{3}\right)$ (Emmanuel, 2003)

Of these, aerosols play a significant role in human mortality/morbidity in urban areas. Several recently published community health studies indicate that significant respiratory and cardiovascular-related problems are associated with exposure to aerosol levels well below the existing standards. These negative effects include premature death, hospital admissions from respiratory causes and increased respiratory symptoms. According to the U.S. Environmental Protection Agency (USEPA, 1999), short-term exposure to particulate matter (PM) can lead to coughing, minor throat irritation and a reduction in lung function. Longterm exposure to particulate matter may increase the rate of respiratory and cardiovascular illness and reduce life span. In the highly polluted Southern California region, eight percent of urban non-smoker lung cancer risk is due to coarse PM in soot from diesel trucks, buses and cars (Ventura County Air Pollution Control District, 2000).

Although research on respiratory health endpoints associated with PM exposure has been very active, it is only in recent years that cardiovascular endpoints have come to command a more urgent focus ( $h t t p: / /$ www. uniltsplepa_ord_ncer_Resea rch_Opportunities_Airborne_Particulate_Matter_Health Effects_Cardiovascular_Mechanisms.htm). A number of epidemio logical studies published in the last few years have examined the relationship between acute PM exposures and cardiovascular disease-related hospital admissions and deaths (Peters, 1997). The results were generally consistent across studies, indicating that increases in ambient levels of PM were associated with increases in adverse effects on the cardiovascular systems.
In addition, controlled human exposure studies and several panel studies of human subjects have examined the relationship between heart and blood measurements and PM exposure. Effects observed in such studies have demonstrated correlations between increases in PM and changes in factors related to inflammatory processes and heart disease, including decreases in heart rate variability in the elderly and increased levels of blood factors involved in coagulation, clotting, and the acute phase response (Peters, 1997, Pope,1999, Dockery, 1999, Peters2001). Studies of laboratory animals exposed to concentrated airborne particulates and other types of PM have found these exposures to be associated with changes in ECG patterns, including elevation of the S-T segment, arrhythmia, increased pulmonary artery systolic pressure, decreased cardiac output, decreased stroke volume and shortened activation recovery interval (Godleski, 2000, Devlin ,2001, Nadziejko,2001). A number of animal models of susceptible populations have been used in toxicology studies examining PM. The studies have shown that animals with compromised health, either genetic or induced, are more susceptible to instilled or inhaled particles, although there is increased animal-to-animal variability in these models (Costa, 1998, Kodavanti, 2001).

Asthma is a common and disabling disease worldwide. The prevalence of asthma has markedly increased over the past 2 decades in adults and in children. (Sears, 1996; Centers for Disease Control and Prevention, 1996) Public concern has been raised recently about environmental influences on asthma control. Children, who breathe in twice as much air as adults, are the most vulnerable (Reese, 1999).

Diesel exhaust fumes can adversely affect children with underlying respiratory illnesses such as asthma, bronchitis, and respiratory infections. Diesel emissions may enhance the effects of some allergens among sensitive individuals. Children's airways are not yet fully developed and have a smaller diameter than those of adults. If airways are inflamed or constricted by asthma, allergies or infections, diesel exhaust may make breathing more difficult. Children may be especially susceptible to adverse respiratory effects following exposure to ultra-fine particulate matter $\left(\mathrm{PM}_{2.5}\right)$ emitted from diesel engines. Nearly $94 \%$ of diesel particulates have diameters less than 2.5 micrometers $(\mathrm{mm})$. The average diameter of diesel particulates is $0.2 \mathrm{~mm}$. the narrower airways of children can be penetrated by small particles that can reach the deep areas of the lungs and be retained there (Wargo, 2001). Higher rates of respiration among children may lead to higher exposure, when measured per unit of their body weight.

Some studies have suggested that episodes of heightened Sulfur Dioxide $\left(\mathrm{SO}_{2}\right)$ levels can impact children especially, causing measurable lung-function declines that may persist for as long as two weeks. Children may also be especially susceptible to a 
weakening of the immune system encouraged by nitrogen dioxide $\left(\mathrm{NO}_{2}\right)$ - specifically, its ability to decrease the body's resistance to lower respiratory infection. Repeated epidemiological studies have linked ambient air pollution, especially fine respirable particles $\left(\mathrm{PM}_{2.5}\right)$ and Ozone, with increased prevalence of cough, bronchitis, and decrements in lung function - especially among youngsters with a history of asthma (Daniels, 2000).

\section{Methods and Materials}

In the present study, we measured exposure levels of urban and rural street users to $\mathrm{SO}_{2}, \mathrm{NO}_{2}$ and Total Suspended Particulates (TSPs) and correlated these with self-reported health survey data. Three kinds of primary and secondary data were collected:

i. Background health data-secondary data to verify the major health issues in Sri Lanka;

ii. Air pollution exposure-Active and Passive sampling data - primary data to estimate exposure;

iii. Health survey data - primary data to elucidate self-perception of health issues.

\section{Background health data}

The background health data pertaining to respiratory and cardiovascular diseases were obtained from the following public health institutions in Sri Lanka:

i. Medical Statistics Unit, Ministry of Health, Sri Lanka.

ii. National Programme for Tuberculosis Control and Chest Diseases Unit, Ministry of Health, Sri Lanka

iii. Annual Health Bulletins, Department of Health Services, Sri Lanka

\section{Air pollution exposure - Active and Passive sampling}

The second category of data (air pollution exposure) was obtained using active and passive sampling techniques (Figure 1). Measurements were taken on every sunny Tuesday over a one and half month period during the dry season. TSP active sampling measurements were carried out using High volume Air Sampler and for $\mathrm{SO}_{2}$ (Turbidimetric method), $\mathrm{NO}_{2}$ (Saltzman method) and $\mathrm{NO}^{2}$ measurements were carried out using Low volume Air Samplers. The average temperature during the measurement period was $30^{\circ} \mathrm{C}$. Data was collected for 8 hours ( 9 a.m. to 5 p.m.) to cover the period of working hours of dust exposure. Air Samplers were mounted at a height of $1.5 \mathrm{~m}$ above ground level.
Air pollution exposure of randomly selected group of street users (urban and rural) was obtained using passive sampling techniques. $\mathrm{SO}_{2}$ and $\mathrm{NO}_{2}$ Passive samplers which contained Whatman $540 \mathrm{~nm}$ absorbing filter papers ( $14 \mathrm{~mm}$ diameter) were coated with $50 \mu \mathrm{l}$ of the absorbing reagent (for $\mathrm{SO}_{2}$ and $\mathrm{NO}_{2}$ different absorbing reagent were used.) and dried in a dessicator. Then the samplers were loaded with stainless steel wire mesh and coated filter pads and sealed with end caps before sending it to the sampling site.

Figure 1: (a) Out door active and (b) / (c) indoor passive sampling devices used in the present study

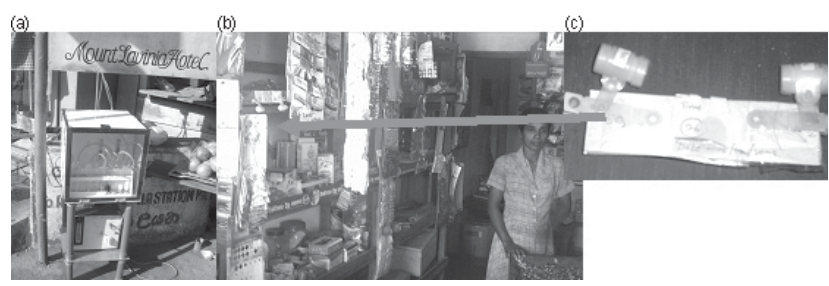

Fifty passive samplers were used to collect simultaneous air quality data at a given location. Ten samplers each were hung in buses, three-wheelers, shops and residences along main roads and semicovered outdoor vendor's huts. The locations were randomly selected and the $\mathrm{SO}_{2}$ and $\mathrm{NO}_{2}$ samplers were kept at a height of $1.5 \mathrm{~m}$ above the ground level or in the breathing zone using holding clips. The sealed end caps were removed at the site before installing the Samplers. Samplers which were kept for one week at the sites. After exposing samplers for a week, they were sealed with end caps and delivered to the Laboratory. The installation and removal times were noted down at each site. The passive sampler data were analyzed using Turbidimetric method $\left(\mathrm{SO}_{2}\right)$ and Saltzman method $\left(\mathrm{NO}_{2}\right)$ with the UV-Visible Spectrophotometer.

\section{Health questionnaire survey}

A random sample of road users were interviewed on their health status, to understand the self-reported health effects of particulate matter on human respiratory diseases. We used a standardized questionnaire for chronic respiratory symptoms developed by the American Thoracic Society, Division of Lung Diseases in 1978 (ATS-DLD 78), modified to suit the conditions in Sri Lanka by a panel of experts in the field. The questionnaire was translated to Sinhala by a professional translator.

Questionnaire was in several sections to gather information on socio-demographic characteristics, present symptoms and the medical diagnosis, tobacco smoking, suggested outcomes of air pollution and occupational history. Exposure to indoor air pollution was ascertained with the help of questions related to the use of mosquito-repellent coil and the type of domestic fuel.

The urban setting selected for the study had a population of 1,465 while that of the rural case was 423 . After proportional allocation for each category $20 \%$ was 
added considering the non responders and exclusions. Thus, the expected number of participants in the urban study was 365 while in the rural study, 241 participants were expected. Questionnaires were administered concurrently with the collection of passive sampler data during a one and half month period of dry weather (early February to mid March 2005). Actual numbers of respondents were 346 and 241 from the urban and the rural location respectively.

\section{Data processing and analysis}

Statistical package for social science (SPSS) and Epiinfo were used to summarize, process and analyze the data. Z-test or t-test were used (significance level = $5 \%$ ) where applicable, to analyze the quantitative data.

\section{Results and Discusion}

\section{Background health data}

Figures 2 and 3 show the trends in mortality (Hospital deaths) and morbidity (hospitalization) patterns respectively, for selected diseases in Colombo. While "heart diseases" remain the number one killer, respiratory diseases such as asthma and acute bronchitis are the primary cause for morbidity in the city. Ischaemic heart disease (Disease Code I20-I25) is the leading cause of mortality from 1995. In 2002, the reported number of deaths is 3,590 (Rate per 100,000 population $=18.9$ ). Since 1999 diseases of the respiratory system (J20$\mathrm{J} 22, \mathrm{~J} 40-\mathrm{J} 98$ ) have remained the sixth leading cause of Hospital deaths. In 2002, the reported number of death due to this category of diseases is 2,117 (Rate per 100,000 population $=11.7$ )
Several studies on death registration in Sri Lanka indicate that many deaths are not registered, particularly in rural areas It is estimated that only $30-40 \%$ of registered deaths occur in government hospitals (Annual Health Bulletin, Department of Health Services, Sri Lanka, 2002). However, even with this limited data in hand, it could be seen that the mortality pattern in Sri Lanka is in a transitional stage. It appears to be changing from a pattern seen in developing countries to a pattern seen in developed countries. The trends in mortality indicate a decrease in deaths resulting from communicable diseases to non communicable diseases such as diseases of the circulatory system, injury and poisoning.

Since 1995, diseases of the respiratory system (J20J22, J40-J98) have remained the second leading cause of hospitalization. In 2002, the reported number of cases in the country are 346,193 (Rate per 100,000 population $=1,826.3$ ).

In Sri Lanka, morbidity data is available only for patients seeking treatment as inpatients in the government hospitals. Morbidity data of patients attending the outpatient departments of government hospitals, ayurvedic institutions and private-sector medical establishments are not routinely collected. In some cases, final diagnoses are not recorded. Therefore morbidity data available in Sri Lanka should be interpreted with caution, considering the above limitations. Even with this limitation, it is apparent that air pollution-related diseases cause notably higher morbidity than any other.

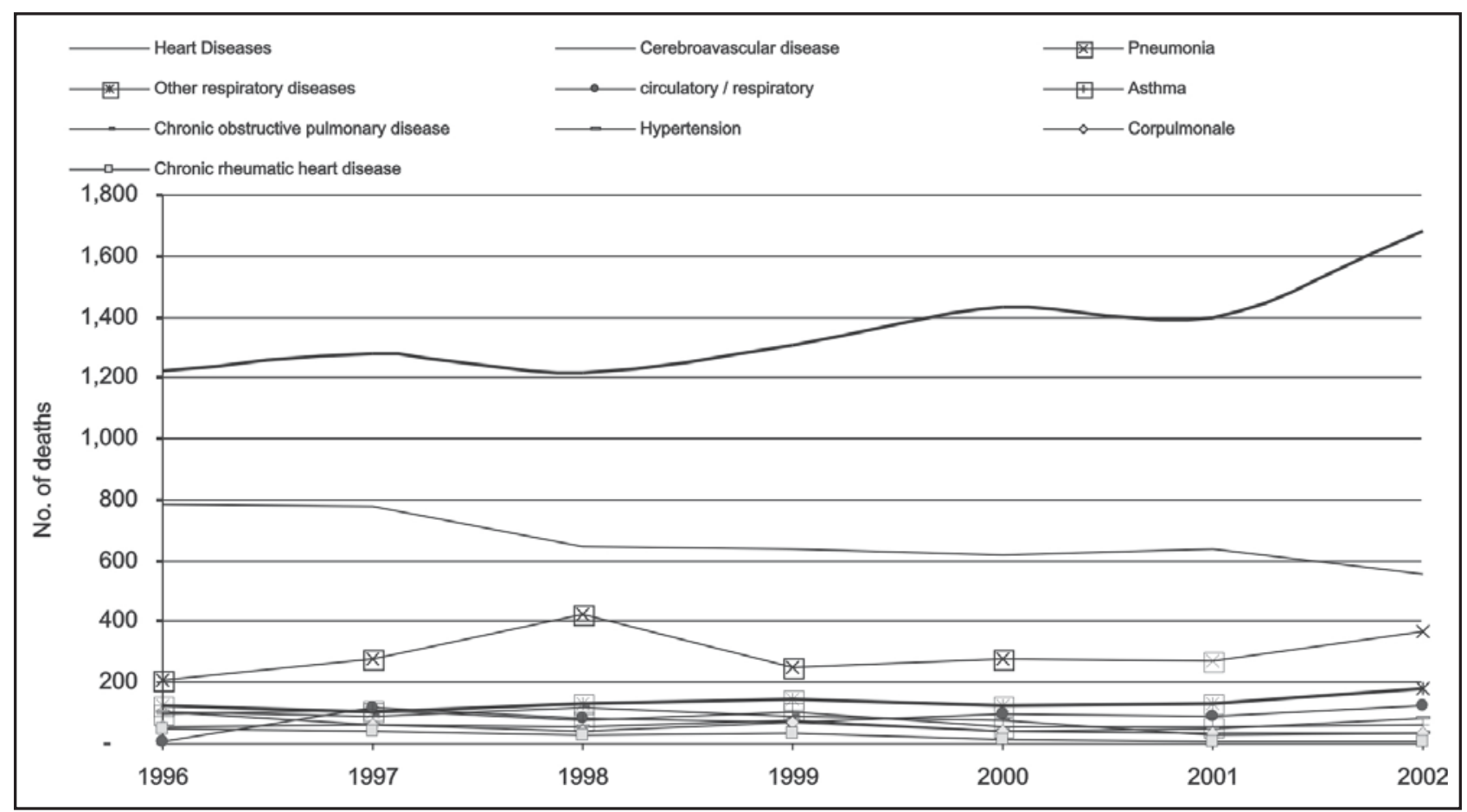

Figure 2: Recent mortality trends for selected diseases in Colombo District Source- Medical Statistics Unit, Ministry of Health, Sri Lanka 


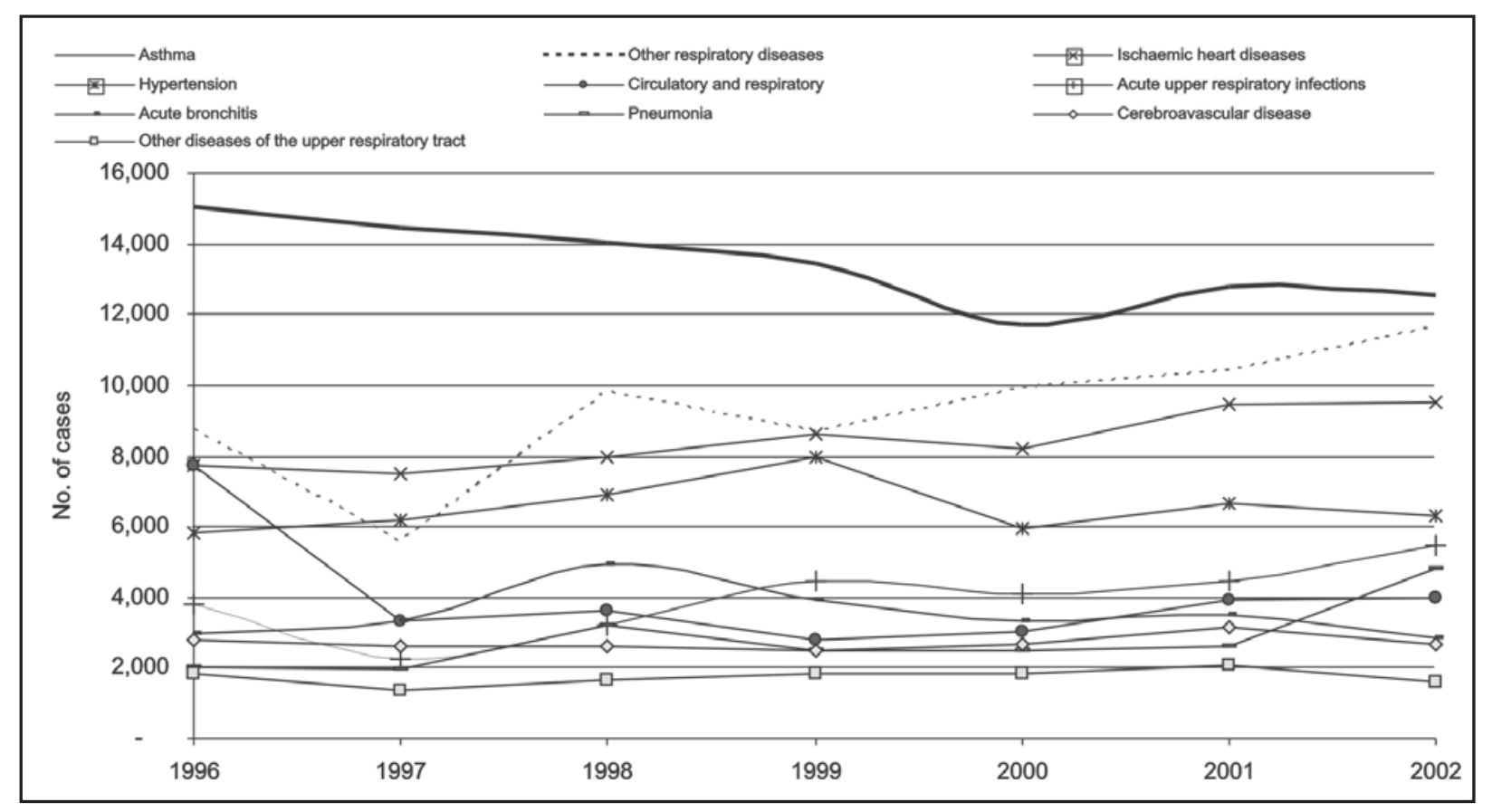

Figure 3: Recent morbidity trends for selected diseases in Colombo District

Source- Medical Statistics Unit, Ministry of Health, Sri Lanka

\section{Air pollution exposure}

Table 1: Active sampling data of TSP, $\mathrm{SO}_{2}, \mathrm{NO}_{2}$ and $\mathrm{NO}$ at the urban location

\begin{tabular}{|c|c|c|c|c|c|c|c|}
\hline Location & Day & $\begin{array}{l}\text { TSP } \\
\mu \mathrm{g} / \mathrm{m}^{3}\end{array}$ & $\begin{array}{l}\mathrm{PM}_{10} \\
\mu \mathrm{g} / \mathrm{m}^{3}\end{array}$ & $\begin{array}{l}\mathrm{PM}_{25} \\
\mu \mathrm{g} / \mathrm{m}^{3}\end{array}$ & $\begin{array}{l}\mathrm{SO}_{2} \\
\mu \mathrm{g} / \mathrm{m}^{3}\end{array}$ & $\begin{array}{l}\mathrm{NO}_{2} \\
\mu \mathrm{g} / \mathrm{m}^{3}\end{array}$ & $\begin{array}{l}\mathrm{NO} \\
\mu \mathrm{g} / \mathrm{m}^{3}\end{array}$ \\
\hline Location 1 (seaside of road) & 1 & 577.78 & 433.3 & 288.9 & 115 & 148.19 & 169.43 \\
\hline \multirow[t]{3}{*}{ Outdoor } & 2 & 446.90 & 335.2 & 223.5 & 131 & 130.94 & 149.05 \\
\hline & 3 & 448.74 & 336.6 & 224.4 & 132 & 93.19 & 119.22 \\
\hline & 4 & 539.34 & 404.5 & 269.7 & 116 & 121.98 & 97 \\
\hline Average & & 503.19 & 377.4 & 251.6 & 123.5 & 123.6 & 133.7 \\
\hline Location 2 (landside of road) & 1 & 479.79 & 359.8 & 239.9 & 110 & 98.71 & 142.45 \\
\hline \multirow[t]{3}{*}{ Outdoor } & 2 & 355.67 & 266.7 & 177.8 & 86 & 105.07 & 139.42 \\
\hline & 3 & 348.67 & 261.5 & 174.3 & 118 & 77.95 & 81.17 \\
\hline & 4 & 383.93 & 287.9 & 191.9 & 105 & 51.3 & 86.36 \\
\hline Average & & 392.02 & 294.0 & 196.0 & 104.8 & 83.3 & 112.4 \\
\hline Location 3 (landside of road) & 1 & 341.30 & 255.9 & 170.7 & & & \\
\hline \multirow[t]{3}{*}{ Indoor } & 2 & 333.96 & 250.5 & 166.9 & & & \\
\hline & 3 & 336.04 & 252.0 & 168.0 & & & \\
\hline & 4 & 332.29 & 249.2 & 166.1 & & & \\
\hline Average & & 335.90 & 251.9 & 167.9 & & & \\
\hline Location 4 (seaside of road) & 1 & 357.78 & 268.3 & 178.8 & & & \\
\hline \multirow{3}{*}{ Indoor } & 2 & 343.24 & 257.4 & 171.6 & & & \\
\hline & 3 & 333.93 & 250.4 & 166.9 & & & \\
\hline & 4 & 343.12 & 257.3 & 171.6 & & & \\
\hline Average & & 344.52 & 258.4 & 172.3 & & & \\
\hline
\end{tabular}

Table 1 shows the results of chemical analysis of active sampling data of TSP, $\mathrm{SO}_{2}, \mathrm{NO}_{2}$ and $\mathrm{NO}$ at the urban location. The average outdoor $\mathrm{SO}_{2}$ level on the seawardside of the main road exceeded the Sri Lankan standard value for 8 hours of $120.0 \mu \mathrm{g} / \mathrm{m}^{3}$. Landward-side has comparatively lower $\mathrm{SO}_{2}$ concentration. This could be due to seaside location being situated facing two bus stops and a three-wheeler parking area along the road. Landside location was situated further away and had fewer idling vehicles in the vicinity. Moreover wind direction also has an effect on the results.

Table 1 also shows that the $\mathrm{NO}_{2}$ and $\mathrm{NO}$ concentrations have not exceeded the Sri Lankan Standard value for 8 hours of $150.0 \mu \mathrm{g} / \mathrm{m}^{3}$. Landside has comparatively lower $\mathrm{NO}_{2}$ and $\mathrm{NO}$ concentrations. $\mathrm{NO}$ is a fresh tailpipe exhaust emission from motor vehicles which is oxidized into $\mathrm{NO}_{2}$ on reaction with atmospheric Oxygen $\left(\mathrm{O}_{2}\right)$. This process takes time. Therefore NO concentration near the road is higher than the $\mathrm{NO}_{2}$ concentration.

On the other hand, TSP levels in all outdoor locations have exceeded the Sri Lankan standard value for 8 hours of $350.0 \mu \mathrm{g} / \mathrm{m}^{3}$. Landside has comparatively lower TSP concentration. The indoor levels of TSP concentrations are very close to the Sri Lankan standard (though still below the threshold). Therefore attention must be paid to minimize the TSP levels both indoors and outdoors. Table 2 shows the results of chemical analysis of passive sampler data at the urban and rural sites. The differences between rural and urban cases are striking. However, a similar pattern was observed within a given site (urban or rural): buses had the highest $\mathrm{NO}_{2}$ and $\mathrm{SO}_{2}$ levels at both sites while residences had the lowest levels. Semi-covered vendor's huts and residence have shown a significant difference between urban and rural sites for $\mathrm{SO}_{2}$ concentration ( $\mathrm{p}=0.007$ and $\left.\mathrm{p}=0.005\right)$. All five categories have shown a significant difference in urban and rural sites for $\mathrm{NO}_{2}$ concentration $(p<0.001)$. The high values of $\mathrm{SO}_{2}$ and $\mathrm{NO}_{2}$ in buses and three wheelers are understandable due to their heavy exposure to fresh tailpipe exhaust emissions from other motor vehicles. The exposure levels of three wheeler drivers were low in comparison to bus drivers. This may be due to the constant movement of the three wheelers, open nature of the vehicle and route characteristics. It was found that most three wheelers studied here plied residential routes while the buses operated on main roads. Moreover three wheelers are mobile most of the time, on account of their high maneuverability. Persons working in roadside establishments too, had high exposure to $\mathrm{SO}_{2}$ and $\mathrm{NO}_{2}$, but the levels varied due to other factors such as location of the shop, design 
features, direction of wind, etc. Semi-covered outdoor vendor's huts also had high exposure levels due to their close proximity to the curbside. Houses have low levels of pollution and this may be due to the presence of vegetation, architectural features of the buildings and lifestyle choices such as keeping the windows shut or covering of permanent ventilation holes using polythene, etc. All rural locations had minimal levels of air pollution.

Table 2: Average $\mathrm{NO}_{2}$ and $\mathrm{SO}_{2}$ Passive Sampling values at urban and rural sites

\begin{tabular}{|c|c|c|c|c|c|c|}
\hline & \multicolumn{2}{|c|}{ Urban } & \multicolumn{2}{|c|}{ Rural } & \multirow[b]{2}{*}{$t$-value } & \multirow[b]{2}{*}{ p } \\
\hline & Mean & SD & Mean & SD & & \\
\hline \multicolumn{7}{|l|}{$\mathrm{SO}_{2}\left(\mu \mathrm{g} / \mathrm{m}^{3}\right)$} \\
\hline Buses & 82.70 & 32.69 & 53.06 & 12.64 & 1.926 & 0.076 \\
\hline Three wheelers & 78.36 & 42.14 & 61.13 & 17.49 & 0.865 & 0.403 \\
\hline Shops & 63.29 & 34.49 & 34.41 & 21.40 & 1.698 & 0.113 \\
\hline Outdoor vendor huts & 63.64 & 25.30 & 22.53 & 10.77 & 3.383 & 0.007 \\
\hline Residences & 37.66 & 8.72 & 20.54 & 10.43 & 3.369 & 0.005 \\
\hline Average & 65.22 & 34.02 & 38.33 & 21.59 & 3.580 & 0.001 \\
\hline \multicolumn{7}{|l|}{$\mathrm{NO}_{2}\left(\mu \mathrm{g} / \mathrm{m}^{3}\right)$} \\
\hline Buses & 57.36 & 14.66 & 18.95 & 7.72 & 5.424 & $<0.001$ \\
\hline Three wheelers & 50.18 & 8.78 & 10.13 & 4.90 & 9.381 & $<0.001$ \\
\hline Shops & 54.91 & 12.71 & 8.91 & 3.68 & 7.795 & $<0.001$ \\
\hline Outdoor vendor huts & 51.22 & 11.98 & 7.01 & 1.02 & 8.117 & $<0.001$ \\
\hline Residences & 35.25 & 7.79 & 5.59 & 1.33 & 8.291 & $<0.001$ \\
\hline Average & 49.69 & 13.55 & 10.12 & 6.28 & 13.792 & $<0.001$ \\
\hline
\end{tabular}

Aerosol levels in urban buses were further analyzed in terms of their route characteristics. Five buses plying on two different bus routes were selected for this purpose - an arterial bus route on the main Galle Road and a suburban bus route running south from Mount Lavinia to Kottawa via rural/semi-urban areas. Table 3 shows that the average $\mathrm{NO}$ and $\mathrm{SO}$ levels found in buses plying these two routes and the ${ }^{2}$ rural route were significantly different. Our analysis indicates that in the urban case, bus drivers are exposed to moderate to high levels of pollution depending on the routes they traveled (suburban vs. urban bus routes). Suburban bus routes and rural bus routes have similar SO concentrations and the relatively high level is probably ${ }^{2}$ due to high sulfur content in diesel.

Table 3: Comparison of passive sampling data on urban, suburban and rural bus routes

\begin{tabular}{lcc}
\hline \multicolumn{1}{c}{ Route } & $\begin{array}{c}\text { Ave. } \mathrm{SO}_{2} \text { Conc. } \\
\left(\mu \mathrm{g} / \mathrm{m}^{3}\right)\end{array}$ & $\begin{array}{c}\text { Ave. } \mathrm{NO}_{2} \text { Conc. } \\
\left(\mu \mathrm{g} / \mathrm{m}^{3}\right)\end{array}$ \\
\hline High risk & 107.56 & 69.38 \\
Suburban & 57.84 & 45.35 \\
Rural & 53.06 & 18.95 \\
\hline
\end{tabular}

SO2 $\left(\mu \mathrm{g} / \mathrm{m}^{3}\right)$ concentrations

\begin{tabular}{lccccc}
\hline & SS & df & MS & F & P \\
\hline Between groups & 9107.14 & 2 & 4553.57 & 13.399 & 0.001 \\
Within groups & 4078.17 & 12 & 339.85 & & \\
\hline Total & 13185.32 & 14 & & & \\
\hline NO2 $\left(\boldsymbol{\mu g} / \mathbf{m}^{\mathbf{3}}\right)$ & concentrations & & & & \\
\hline \multicolumn{7}{c}{$\mathbf{S S}$} & df & MS & F & P \\
\hline Between groups & 6362.49 & 2 & 3181.24 & 52.283 & $<0.001$ \\
Within groups & 730.16 & 12 & 60.85 & & \\
\hline Total & 7092.66 & 14 & & & \\
\hline
\end{tabular}

\section{Health questionnaire survey}

It is suspected that air quality might be an indirect cause for illness while lifestyle and dietary factors may have a more direct impact on mortality and morbidity. In order to elucidate the micro-level picture, we compared the self-reported symptoms and medical diagnosis of a randomly selected group of street users (urban and rural), using a structured questionnaire. Table 4 shows a comparison of self reported symptoms and illnesses among various categories of street users in urban and rural sites. It could be seen that urban dwellers report higher prevalence of respiratory illnesses. Urban dwellers also report higher prevalence of cough and phlegm than rural dwellers $(p<0.001)$. The differences between the two groups in terms of other medical conditions are not statistically significant.

Table 4: Comparison of Self-reported medical conditions among city dwellers and rural dwellers

\begin{tabular}{|c|c|c|c|c|c|c|}
\hline \multirow[t]{2}{*}{ Symptom } & \multicolumn{2}{|c|}{$\begin{array}{l}\text { City Dwellers } \\
\qquad(\mathrm{N}=346)\end{array}$} & \multicolumn{2}{|c|}{$\begin{array}{l}\text { Rural Dwellers } \\
\qquad(\mathrm{N}=\mathbf{2 1 1})\end{array}$} & \multirow[t]{2}{*}{$\begin{array}{c}\text { OR } \\
(95 \% \mathrm{Cl})\end{array}$} & \multirow[t]{2}{*}{$\begin{array}{l}\text { Prob- } \\
\text { ability }\end{array}$} \\
\hline & Yes & No & Yes & No & & \\
\hline Cough & $\begin{array}{c}171 \\
(49.4 \%)\end{array}$ & $\begin{array}{c}175 \\
(50.6 \%)\end{array}$ & $\begin{array}{c}47 \\
(22.3 \%)\end{array}$ & $\begin{array}{c}164 \\
(77.7 \%)\end{array}$ & $\begin{array}{c}3.43 \\
(2.29-5.15)\end{array}$ & $<0.001$ \\
\hline Phlegm & $\begin{array}{c}131 \\
(37.8 \%)\end{array}$ & $\begin{array}{c}215 \\
(62.2 \%)\end{array}$ & $\begin{array}{c}46 \\
(21.8 \%)\end{array}$ & $\begin{array}{c}165 \\
(78.2 \%)\end{array}$ & $\begin{array}{c}2.19 \\
(1.45-3.30)\end{array}$ & $<0.001$ \\
\hline Episode of cough \& phlegm & $\begin{array}{c}55 \\
(15.9 \%)\end{array}$ & $\begin{array}{c}291 \\
(84.1 \%)\end{array}$ & $\begin{array}{c}26 \\
(12.3 \%)\end{array}$ & $\begin{array}{c}185 \\
(87.7 \%)\end{array}$ & $\begin{array}{c}1.34 \\
(0.79-2.29)\end{array}$ & 0.245 \\
\hline Wheezing & $\begin{array}{c}71 \\
(20.5 \%)\end{array}$ & $\begin{array}{c}275 \\
(79.5 \%)\end{array}$ & $\begin{array}{c}29 \\
(13.7 \%)\end{array}$ & $\begin{array}{c}182 \\
(86.3 \%)\end{array}$ & $\begin{array}{c}1.62 \\
(0.99-2.67)\end{array}$ & 0.043 \\
\hline \multirow[t]{2}{*}{ Breathlessness } & 35 & 311 & 14 & 197 & 1.58 & 0.159 \\
\hline & $(10.1 \%)$ & $(89.9 \%)$ & $(6.6 \%)$ & $(93.4 \%)$ & $(0.80-3.18)$ & \\
\hline
\end{tabular}

Figure 4 shows a comparison of self-reported symptoms and illnesses among 5 segments of street users at or near the urban measurement site. Cough, phlegm and wheezing are common among urban shop assistants and bus drivers where the levels of exposure to polluted aerosol are also very high. Passive sampling results show that street vendors' exposure levels were high and they also report higher prevalence of wheezing and breathlessness.

In the case of rural dwellers (Figure 5), there was no marked increase in respiratory illnesses in contrast with urban dwellers. Rural bus drivers and outdoor vendors have reported moderate cough and phlegm levels. Reported incidence of respiratory illnesses among rural residents is high when compared to other rural respondents. This may be explained by their lifestyle with high use of wood as cooking fuel and participation in agricultural activities where pollen exposures may occur.

Table 5 shows a comparison of cough prevalence among city and rural dwellers. There appears to be no significant difference in self reported symptoms of cough and phlegm between these two groups except in the very young and with respect to type of cooking fuel used. Rural dwellers who use wood as their fuel type reported considerably high prevalence of cough and phlegm. Therefore respiratory symptoms association might be overridden by local within-city risk factors of presence of wood users as cooking fuel in the rural site. 
Within these limitations, certain tentative policy implications and guidelines can be drawn. It must be kept in mind that the focus of the urban planning / landscape design initiatives using street treatment options is to lower the human exposure. An economical way to achieve this aim is to concentrate on stretches of roads where pedestrians are likely to be numerous. Traffic junctions are especially important on account of the presence of large numbers of pedestrians as well as the typically slow vehicular speeds. From an air quality point of view it may be more beneficial to facilitate a smooth flow of vehicular traffic in such places. Although traffic stoppage at junctions is inevitable, strategies for the smooth flow of traffic may mitigate the exposures to Respirable Particulate Matter at junctions.

Street-facing shops and road side houses should have dust-control design features to enhance indoor air quality and should be designed taking into consideration meteorological factors such as direction of the wind.

The levels of exposure along major highways are likely to be above safety limits. As such, development options along major arteries may have to be re-evaluated. Semicovered outdoor vendor's huts should be located away from curb-side. The bus-stops near the urban site need to be rationalized and paving options at the bus park have to be re-evaluated.

Height of the building should also be taken into consideration: the urban site is near the coastal area, and therefore there is a dilution of air pollutants due to sea breeze. High rise buildings may interfere with wind flow and accumulation of pollutants may occur within the street canyons. However high rise buildings increases the shading and increase thermal comfort. Therefore care has to be taken in the control of height of buildings. Further research - including computer modeling - is needed in this respect.

Another possibility to control transportation-induced air pollution is to use urban vegetation. While the development of vegetated areas could have negative impacts on air quality by reducing vegetative and soil absorptive capacity and increasing emissions and ambient air temperatures, proper management of vegetation in urban areas has the potential to improve air quality (Smith, 1984). It is necessary to plant trees in areas where high levels of exposure to air pollution are likely occur. However, care must be taken so as to avoid pollutant sensitive species.

Proper urban planning controls are needed for the city area including special landscape on small parks with trees and bushes and a regieme of regular maintenance (especially removal of sand from road side) is also needed. Priority for such actions may be given to commercial areas where large concentration of pedestrians occur. Further research is needed with respect to urban landscape and pollution control (e.g: where to plant, how many trees to be planted, height of vegetation, suitable varieties for the urban setting, etc). In the final analysis, motorized transportation has a greater tendency to pollute. As such, it is necessary to expand the use of non-motorized modes of transportation. Promoting greater use of bicycling and walking as the best method of commute will be helpful. It is also necessary to increase the percentage of streets with safe bike lanes and sidewalks to promote bicycle and pedestrian modes of commuting. Paved sidewalks will be particularly beneficial in reducing coarse particulates.

Other challenges that need to be overcome include, reducing the number of people who travel by singleoccupant vehicles, encouraging travel by mass transportation modes and office and school vans, and decreasing the number of trips that motorists make. $A$ rational land-use plan is critical to reduce the number of trips residents make between home, work, shopping and recreation.

Finally, there is also a need to increase public awareness of the ill effects of air pollution. General air pollution awareness programmes are needed in this regard. This will help to change the attitudes towards air pollution and the primary factors that cause them. It is hoped that studies such as the present one may increase public awareness and lead to cooperative action involving both the local and central governments and the private sector.

\section{Acknowledgments}

We wish to acknowledge the following for providing resources and support to complete this work successfully: M.D. Clarence Perera, Head, Environment Division and Mr. R.P. Samarakkody, National Building Research Organization (NBRO); Dr. Ruwan Wijayamuni, Chief Medical Officer of Health, Colombo Municipal Council.

Mr. A.T.R.Fernando, Technical Officer, NBRO, Mr. Miyuru Weerasinhe, Post-graduate student, Department of Architecture, University of Moratuwa, Mr. Gunaratne, Mr. Jayawardana (both from the Medical Officer of Health Office, Padiyathalawa) assisted in carrying out the air quality measurements and administered the surveys.

We extend our grateful appreciation to all those who contributed to this study.

\section{References}

Annual Health Bulletin, (2001). Department of Health Services, Sri Lanka

Centers for Disease Control and Prevention (1996). Asthma mortality and hospitalization among children and young adults: United States, 19801993. MMWR Morb Mortal Wkly Rep 45:350353 
Costa, D.L., Kodavanti, U.P., Bromberg, P.A., (1998). Rodent models of cardiopulmonary disease: their potential applicability in studies of air pollutant susceptibility. Environ. Health Perspect. 106 Suppl1:111-30 Review

Costa, D.L., Kodavanti, U.P., Bromberg, P.A., (1998). Rodent models of cardiopulmonary disease: their potential applicability in studies of air pollutant susceptibility. Environ. Health Perspect. 106 Suppl1:111-30 Review

Daniels, M.J., Dominici, F., Samet, J.M., Zeger, S.L., (2000). Estimating particulate matter-mortality dose-response curves and threshold levels: an analysis of daily time-series for the 20 largest US cities, Am J Epidemiol 152: 397-406

Devlin, R.B., Johnson, T.A., Ghio, A., Huang, Y.C., Costa, D.L., Bromberg, P., Cascio, W. (2001). Pulmonary and cardiac changes in pigs exposed to residual oil fly ash. Amer.J. Respir. and Critical Care Med. 163:A 311

Dockery, D.W., Pope, C.A.III., Kanner, R.E., Vollegas, G.M., Schwartz, J., (1999). Oxygen saturation, pulse rate, and particulate air pollution: a daily time-series panel study. Am J. Respir. Crit. Care Med. 159: 365-372

Godleski, J.J., Verrier, R.L., Koutrakis. P., Catalano. P., (2000). Mechanisms of Morbidity and Mortality from Exposure to Ambient Air Particles. Cambridge, MA: Health Effects Institute; Research Report No. 91

http://www.uniltsplepa ord ncer Research Opportunities Airborne Particulate Matter Health Effects CardiovascularMechanisms.htm (searched date 18/02/2005)

Jayawardana, K., (2003). Trends of air quality in the city of Colombo, Sri Lanka Association for the Advancement of Science, Annual Session 2003

Kodavanti, U.P., Costa, D.L., 2001. Rodent models of susceptibility: what is their place in inhalation toxicology. Respir. Physiol. 128(1):57-70 Review

Nadziejko, C., Chen, L.C., Fang, K., Gordon, T., (2001). Comparison of acute cardiovascular effects of concentrated ambient particulate matter and tobacco smoke in hypertensive rats. Toxicol. Sci. 60:162 2001
U.S. Environmental Protection Agency (USEPA), (1999). National Air Quality and Emissions Trends Report, Washington, DC: U.S. Environmental Protection Agency

Peters, A., Doring, A., Wichmann, H.E., Koenig, W., (1997). Increased plasma viscosity during air pollution episode: a link to mortality. Lancet 349:1582-1587

Peters, A., Frohlich, M., Doring, A., Immervoll, T., Wichmann, H.E., Hutchinson, W., Pepys, M.B., Koenig, W., (2001). Particulate air pollution is associated with an acute phase response in men: results from the MONICAAugsburg Study. Eur. Heart J.:22:1198-1204

Pope, C.A. III., Verrier, R.L., Lovett, E.G., Larson, A.C., Raizenne, M.E., Kanner, R.E., Schwartz, J., Villegas, G.M., Gold, D.R., Dockery, D.W., (1999). Heart rate variability associated with particulate air pollution. Am. Heart J. 138:890-899

Prins, D.S., Rombout, P.J..A., Kamers, P.G.N., Heijna-Merkus E., (1984). Fine dust. Criterion Document Air. Bilthoven, Netherlands

Reese, A., (1999). Bad air Ddays-air pollution in the United States, The Environmental Magazine, November 1999

Safetyline Institute, (1993). Work place safety, http:/ /www.safetyline.gov (accessed on 3rd March 2004)

Sears, M.R., (1996). Epidemiological trends in asthma, Can Respir J; 3:261-268

U.S. Environmental Protection Agency, (1996). Air quality criteria for particulate matter. Research Triangle Park, NC: National Center for Environmental Assessment-RTP Office; Report Nos. EPA/600/P-95/001aF-cF

Ventura county Air Pollution Control District, 2000, health effects, http://www.vcapcd.org/ health.htm (accessed on 18th February 2005)

Wargo, J., (2001). Children's Exposure to Diesel Exhaust on School Buses, Environment \& Human Health, Inc. Feb 2, 2002. 